\title{
Bulk Molybdenum Field Emitters by Inductively Coupled Plasma Etching
}

\author{
Ningli Zhu ${ }^{1,2}$, Matthew T. Cole ${ }^{2}$, William I. Milne ${ }^{2,3}$ and Jing Chen ${ }^{1}$ \\ ${ }^{1}$ Institute of Microelectronics, Peking University, Beijing, 100871, P. R. China \\ ${ }^{2}$ Electrical Engineering Division, Department of Engineering, University of Cambridge, \\ United Kingdom \\ ${ }^{3}$ College of Information Science and Electronic Engineering, Zhejiang University, \\ 310027, Hangzhou, P. R. China
}

\begin{abstract}
In this work we report on the fabrication of inductively coupled plasma (ICP) etched, diode-type, bulk molybdenum field emitter arrays. Emitter etching conditions as a function of etching mask geometry and process conditions were systematically investigated. For optimized uniformity, aspect ratios of $>10$ were achieved, with 25.5 nm-radius tips realised for masks consisting of aperture arrays some $4.45 \mu \mathrm{m}$ in diameter and whose field electron emission performance has been herein assessed.
\end{abstract}

Keywords: inductively coupled plasma, molybdenum, field electron emission 


\section{Introduction}

Molding[1-3], through-aperture evaporation[4-9], dry etching[10-15], hot-embossing[16], stamping[17], and wet etching $[18,19]$ have all been proposed as means of fabricating Spindt-type field emission arrays (FEA). In the case of molding techniques[1-3], tips are formed by the deposition of the emitter material on mask protrusions. Pyramid emitters have been produced using Si mold masks, though significant field distortion and parasitic edge emission have been noted in such devices. Surface roughness, apex sharpness, areal uniformity, and sample-to-sample reproducibility are often less dependent on the process conditions in hard mask etching approaches. The curvature of the emitter apex can be further tailored for optimal electron emission and temporal stability through the inclusion of designed micro and nano adlayers[20]. Various evaporation methods[4-9] have been developed, largely based on the use of metal sacrificial adlayers deposited at oblique angles on rotating substrates. The final thin film emitters are subsequently evaporated at normal incidence, with a conical metal tip forming at the aperture base. Here the emitter and gate electrode are self-aligned following the removal of the sacrificial layer through wet etching. In dry etching[11-15], the aperture is masked at the center and exposed at the periphery to mediate isotopic removal of the emitter material. As a result, a conicallike emitter is formed at the base of the aperture. In such systems, due to notable ion bombardment, such surfaces often have particularly high surface roughness. Various photoresist-based[16, 17] approaches have also been proposed, and have proven capable of realising tip radii of $<50 \mathrm{~nm}$ [17]. Since resist can be spin-coated or printed, these emitters often have a high degree of fidelity to the source mask, with negligible damage to the molding mask. Wet etched ${ }^{17,18}$ wedge-shaped emitters, with radius of curvature in 
the range of $30-40 \mathrm{~nm}$, have been demonstrated[18]. Since such wedge emitter arrays were fabricated by under-cutting using anisotropic wet etching, less surface damage results thereby reducing the surface roughness dramatically. However, the necessary space for the mask pattern limits the attainable FEA packing density, and hence the maximum current density. To date, simultaneously high current, high current density, long-term operation, and continuous emission have yet to be reported using such conventional processes. New fabrication processes are required. Major challenges remain. These include issues with low fabrication yield, non-uniform emission, tip burn-out and apex erosion. A high yield process for the fabrication of large-area FEA is critically required, particularly from low cost, bulk metal substrates.

Molybdenum and silicon, and layered combinations thereof, are commonly used for realizing Spindt-type FEAs. Various reactive gas mixtures have been proposed to realize high selectivity and subsequently high aspect ratio morphologies. The use of $\mathrm{CCl}_{4} / \mathrm{O}_{2}$ for the preferential etching of $\mathrm{Mo}$ over $\mathrm{Si}$ and $\mathrm{SiO}_{2}$ in a cathode coupled parallel plate reactor has been reported[21]. Here the lateral etch rate was approximately six times less than that in the vertical direction. Others have exploited the plasma etching chemistry of Mo using $\mathrm{CCl}_{2} \mathrm{~F}_{2} / \mathrm{O}_{2}, \mathrm{SF}_{6} / \mathrm{Cl}_{2}$ and $\mathrm{SF}_{6} / \mathrm{Cl}_{2} / \mathrm{O}_{2}$ [22]. Molybdenum oxychlorides are formed when $\mathrm{Mo}$ is exposed to mixtures of $\mathrm{CCl}_{4} / \mathrm{Cl}_{2}$ and $\mathrm{O}_{2}$. Oxychlorides have a higher saturated vapour pressure than molybdenum chlorides and thus become volatile at elevated temperatures. Various reports have also shown that the Mo etch rate is dominated by low energetic, yet highly chemically active species[21, 22]. More recently, deep reactive ion etching of Mo using $\mathrm{SF}_{6}$ was reported for high aspect ratio structures, 
with mesa larger than $10 \mu \mathrm{m}$ produced[23, 24]. In the case of Mo, it was shown that reduced undercutting and high selectivity over $\mathrm{SiO}_{2}$ were achieved when $\mathrm{SF}_{6}$ was mixed with $\mathrm{BCl}_{3}$ and Ar. Upon mixing of $\mathrm{SF}_{6}$ with $\mathrm{O}_{2}$, a less volatile $\mathrm{MoOF}_{4}$ product was generated. In the present paper, inductively coupled plasma etching of bulk molybdenum is reported for the fabrication of field electron emission arrays. Systematic studies on the morphology effects of gas flow rate, mask geometry, process pressure, ion energy and plasma density are studied, resulting in promising preliminary field emission data from near-optimal array geometries.

\section{Experimental}

The fabrication process is reported in detailed elsewhere[10, 11]. For brevity, and as shown in Fig. 1(a), a double-side-polished, $400 \mu \mathrm{m}$ thick, 4-inch high purity $(99.95 \%)$ Mo wafer was first coated with an evaporated $500 \mathrm{~nm}$ thick Al film to form an etch hard mask. Tip arrays were subsequently patterned by photolithography (Fig. 1b-c), with the Al patterned by dry etching in $\mathrm{CH}_{3} \mathrm{~F}$ plasma (Fig. 1d). The Mo-FEA tips were etched using an anisotropic $\mathrm{SF}_{6}$ dry etch in a commercial ICP etcher (Sentech PTSA 500) (Fig. 1e). Only $\mathrm{SF}_{6}$ was used as an etching agent herein. All additional carrier gases where found to be largely inert with regards to the present etch system under study. All etching experiments were conducted on 5 x $5 \mathrm{~mm}$ samples. Finally, ultrasonication (15 W) for 60 s removed the residual Al following the ICP etch (Fig. 1(f)).

As shown in Fig. 1(g), d denotes the distance from the tip to anode, $\mathrm{r}$ is the tip radius, and $\mathrm{p}$ is the inter-tip pitch $(5-20 \mu \mathrm{m})$. Tip geometries were assessed by scanning electron 
microscopy, with a subset validated using atomic force microscopy for ensured accuracy. For all samples, aspect ratios were determined by measuring the tip height and base width, extracted via SEM, at a fixed beam voltage $(10 \mathrm{kV})$ and stage tilt $\left(45^{\circ}\right)$. Al was used as the etch mask for its high selectivity over Mo[25]. Since the Al mask geometry largely affects the morphology of the realised emitters, various mask geometries of increasing vertex number - including triangle, square, hexagon, octagon, and circle - were investigated to control the geometry of the resultant tips. For all patterns the effective radius of the mask geometries was $2.5-10 \mu \mathrm{m}$. To evaluate the optimal process conditions, the dependence of the aspect ratio $(A R)$ and etch rate $\left(R_{E}\right)$ on mask geometry and process conditions (temperature, gas pressure, $\mathrm{RF}$ power, ICP power and $\mathrm{SF}_{6}$ flow rate) were investigated.

\section{Results and discussion}

Both the vertical and lateral etch rates depend critically on the Al mask geometry. To optimize the mask geometry, the tip aspect ratio at different locations of the etched pattern was measured via scanning electron microscopy. The micrographs of each MoFEA for each mask geometry were fabricated using equivalent etch conditions, as shown in Fig. 1(h-l). The geometry of the etching mask clearly affects the resulting emitter morphology. The emitter profiles adopt a similar geometry to their defining masks; for example, emitters with a triangular mask become pyramidal in geometry. Figure 2(a) summarizes the AR as a function of mask geometry. Circular masks achieve the highest aspect ratio, of up to 10 , though a large variation is evident, compared to a typical aspect 
ratio of $1.8-4$ for other geometries considered. For the triangle mask, the tips have an aspect ratio around 6 and a height of $4-8 \mu \mathrm{m}$.

For bulk Mo ICP etching, $\mathrm{SF}_{6}$ is the principle feedstock of fluorine radicals, reacting with the Mo substrate forming volatile $\mathrm{MoF}_{6}$. Compounds such as $\mathrm{MoF}_{4}, \mathrm{MoF}_{5}$, and $\mathrm{MoF}_{6}$ are formed by successive fluorination of Mo[22], as described by;

$$
\mathrm{MoF}_{\mathrm{n}}+\mathrm{F} \longrightarrow \mathrm{MoF}_{\mathrm{n}+1}, \mathrm{n}=0,1,2,3,4,5 \text {. }
$$

Figure 2(b, c, d) shows the measured $A R$ and $R_{E}$ of the as-synthesised Mo tips as a function of $\mathrm{SF}_{6}$ flow rate, temperature, and chamber pressure. The effects of temperature on the etching characteristics are outlined in Fig, 2(c). The etching rate at $45^{\circ} \mathrm{C}$ was 0.56 $\mu \mathrm{m} / \mathrm{min}$, twice that at $20^{\circ} \mathrm{C}(0.24 \mu \mathrm{m} / \mathrm{min})$. Nevertheless, the etch rate does not significantly increase for temperatures in excess of $50^{\circ} \mathrm{C}$. Molybdenum etching relies on a variety of inter-related radical induced chemical processes. As shown in Fig. 2(b), we find that the vertical $\mathrm{R}_{\mathrm{E}}$ increases near-linearly with increasing $\mathrm{SF}_{6}$ flow rate. As a result, higher AR emitters were realized using higher flow rates, as illustrated. Increasing the mass flow rate of $\mathrm{SF}_{6}$ tends to increase, to a degree, $\mathrm{R}_{\mathrm{E}}$ by increasing the exposure to the etching species, whilst also increasing the rate of product removal, the latter of which would otherwise reduce $R_{E}$ via etch passivation. The rate of radical formation, and the lifetime of the associated molecular dissociations, is a major contributor to the observed enhanced chemical reactivity, particularly at low, near-room temperatures. Though requiring further detailed studies, it is probable that radical formation tails off for temperatures $>50^{\circ} \mathrm{C}$. Various $\operatorname{MoF}_{\mathrm{n}}(\mathrm{n}=4,5,6)$ compounds are formed during successive fluorination of molybdenum. The highly volatile latter most compound of 
these, $\mathrm{MoF}_{6}$, possibly plays a central role in regulating, mediating or passivating in the present etch system. $\mathrm{MoF}_{6}$ undergoes a phase transition at $37^{\circ} \mathrm{C}$. At elevated process temperatures, the $\mathrm{MoF}_{6}$ residency time may, as a result, change, therein reducing the etch rate as evidenced.

As noted in Figure 2(d), a maximum in the etch rate occurs at around 30 mTorr. For the given chamber characteristic dimensions and associated flow regimes, Langmuir probe measurements, conducted in comparable chambers, provided insight into the plasma characteristics. Low chamber pressures led to an increase in the ion mean-free-path, producing highly anisotropic etches, though at low etch rates. Increasing the plasma density, by increasing the chamber pressure, tended to broadly increase the etch rate. However, at elevated pressures (>30 mTorr) high surface absorption and etch passivating species tended to contribute towards a reduction in etch rate by ineffectual removal of these species. Moreover, as the chamber pressure increased, etch mediating energetic ions underwent additional collisions, losing kinetic energy and directionality. This reduced the etch rate whilst increasing etch isotropy, hence reducing AR. As the pressure increased from 10 to 40 mTorr, the self-induced DC bias across the plasma sheath decreased from 61 to $10 \mathrm{~V}$, corroborating such a reduction in ion energy and the observed change in etch rate alongside the continual reduction in AR.

The RF and ICP power were used to accurately control the plasma ion energy and ion density. Ion energy was adjusted by varying the RF power applied to the stage, and is related to $\left|V_{\mathrm{dc}}\right|$ across the plasma sheath. The RF power was increased from $10 \mathrm{~W}$ to 40 
$\mathrm{W}$ while the $\left|\mathrm{V}_{\mathrm{dc}}\right|$ increased from $19 \mathrm{~V}$ to $36 \mathrm{~V}$. Scanning electron micrographs of hexagonal, triangular, and circular geometries are shown in Fig.3 (a-c). As shown in Fig. 3(d), $R_{E}$ increases with increasing $R F$ power as the generated energetic ions partially assist in Mo removal. However, energetic ions generated at high RF power likely induce surface damage and therein degrade device performance. The etch rate subsequently slowed, and ultimately plateaued as the RF power further increased. Meanwhile, the increase in $\mathrm{AR}$ was significant when the RF power increased from 0 to $20 \mathrm{~W}$, though this too plateaued thereafter.

The effects of ICP power where also considered as a means of controlling the ion density and therein adjust the etch rate. The ion density is principally controlled by the ICP power, whereas the RF power controls the ion energy. A $40 \mathrm{~W}$ RF and circular mask $(2.25 \mu \mathrm{m})$ was chosen to study the effects of the ICP power. Figures 4(a), (b) and (c) show SEM micrographs of the Mo tip etch profiles, etched at $700 \mathrm{~W}, 800 \mathrm{~W}$ and $900 \mathrm{~W}$ ICP power, respectively. Each micrograph shows the etch profile prior to removal of the Al hard mask. The insets show SEMs of single tips in the arrays. The tip AR tended to increase with ICP power. With increasing ICP power, plasma density and, therein, the proportion of reactive radicals increased resulting in an increase in the etch rate. MoFEAs, with a pitch of $7.5 \mu \mathrm{m}$, were realized with high spatial uniformity and aspect ratios consistently greater than 10, with a typical mean tip radius of $25.5 \mathrm{~nm}$. In Fig. 4(d), a maximum occurred the AR and $\mathrm{R}_{\mathrm{E}}$ at $900 \mathrm{~W}$ ICP power. When the ICP power increased to more than $1000 \mathrm{~W}$, both $\mathrm{R}_{\mathrm{E}}$ and $\mathrm{AR}$ decreased, possibly due either to reduced ion energies, therein reducing the sputter desorption of etch products, or higher plasma flux 
that sputtered reactive species from the surface prior to reaction[26]. The morphologies of the fabricated arrays compared favorably with other well-established tip forming techniques[27, 28]. The present mask selectivity was $>20$. Though a higher surface roughness was evident compared to many Si-supported thin film approaches, we anticipate that with further optimisation of the etch process and improved cleaning, preparation and hard mask adhesion, such roughness can be reduced to a comparable level with incumbent thin film techniques. Etch uniformity, as assessed by comparing the standard deviation in emitter morphology and the degree of surface roughness, was found largely similar to other published works.

Using the optimized Mo-FEA devices, to validate aspect-ratio mediated enhancement, preliminary field electron emission performance was measured in a simple diode configuration at a base pressure of $10^{-8}$ mbar. The anode-cathode distance was $600 \mu \mathrm{m}$. An emission area of $100 \mathrm{~mm}^{2}$ was used throughout. To ensure thorough out-gassing, samples were pre-heated to $300^{\circ} \mathrm{C}$ for $5 \mathrm{~h}$ under vacuum. Two nominal samples were chosen to investigate the field emission performance. Circular mask geometries, of differing etch conditions and therein disparate ARs, were considered. The typical tip aspect ratio was 1.12 with a radius of around $75 \mathrm{~nm}$ for the low AR sample. Fig. 5(a) shows the corresponding I-V spectrum. A maximum current of $32 \mu \mathrm{A}$ was measured at

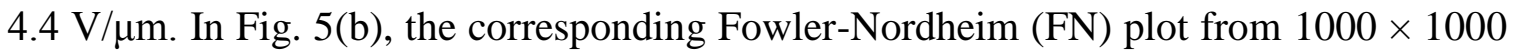
emitters is shown. For the second, high AR sample, the emitter aspect ratio was 2.02, and the tip apex sharpness around $55 \mathrm{~nm}$. The field emission current reached a maximum of $140 \mu \mathrm{A}$ at $5.5 \mathrm{~V} / \mu \mathrm{m}$ (Fig. 5(c)). The measured emission current conforms well to 
established FN behavior $\left(\mathrm{R}^{2}=0.96\right)$. The corresponding FN plot from an array of $1000 \times$ 1000 emitters is shown in Fig. 5(d). As expected, the higher aspect ratio and smaller tip radius tended to improve the emission characteristics. From Figures 5(a) and (c) we note a decrease in threshold field following morphology optimization; the threshold field of a typical high AR array was approximately $4.4 \mathrm{~V} / \mu \mathrm{m}$, some $80 \%$ smaller than the threshold field from the low AR array.

\section{Conclusions}

Here a bulk molybdenum ICP etching process has been developed to fabricate high aspect ratio field electron emission arrays. $\mathrm{SF}_{6}$ flow rate, $\mathrm{RF}$ power, ICP power, temperature and pressure have been investigated to determine their first-order effects on etching rate and profile isotropy. By controlling the etch mask geometry and the etch conditions in the plasma, Mo emitters have been fabricated with nanoengineered sharpness and aspect ratios necessary for high electron emission currents. With a preliminary optimized bulk molybdenum ICP etching process, a high etching rate of up to $0.51 \mu \mathrm{m} / \mathrm{min}$ has been achieved with an aspect ratio of $>10$. Samples demonstrated that high aspect ratio and smaller tip radius offered improved emission currents relative to their low aspect ratio counterparts. It is hoped that the facile fabrication processes outlined herein will allow for the realization of low cost, bulk metal FEAs for use in continuous beam field emission applications. 


\section{Acknowledgements}

The authors thank the staff at the National Center for Nanoscience and Technology, Beijing, for sample fabrication and assisting in metrology. 


\section{List of Captions}

Fig. 1: (a-f) Cross-sectional scheme depicting the fabrication of the bulk Mo-FEAs (g) Schematic depicting the critical emitter dimensions (h-l) Scanning electron micrographs of etched emitters (Process conditions: RF $10 \mathrm{~W}, \mathrm{ICP} 700 \mathrm{~W}, \mathrm{SF}_{6} 30 \mathrm{sccm}, 30^{\circ} \mathrm{C}, 10$ mTorr, etch time 900s).

Fig. 2: (a) Variation in aspect ratio as a function of mask geometry. (b) Etch rate and aspect ratio variation with $\mathrm{SF}_{6}$ flow rate. Triangular masked samples $(1.25 \mu \mathrm{m})$ were etched with $20 \mathrm{~W}$ RF power, $750 \mathrm{~W}$ ICP power, at $30^{\circ} \mathrm{C}$ (c) Variation in etch rate with temperature. (d) Variation in etch rate and aspect ratio as a function of Chamber Pressure. Samples with circular masks $(2.75 \mu \mathrm{m})$ were etched in a $\mathrm{SF}_{6}$ plasma at 45 mTorr with 50 W RF power, $30^{\circ} \mathrm{C}$.

Fig. 3: (a-c) Scanning electron micrographs of typical etched emitters with various mask geometries; (a) hexagonal, (b) triangular, and (c) circular. (Process parameters: RF $30 \mathrm{~W}$, ICP $700 \mathrm{~W}, \mathrm{SF}_{6} 50 \mathrm{sccm}, 30^{\circ} \mathrm{C}, 20 \mathrm{mTorr}$, etch time 720s) (g) Variation in etch rate and aspect ratio with $\mathrm{RF}$ power. Samples with square mask $(2.5 \mu \mathrm{m})$ were etched in a $\mathrm{SF}_{6}$ plasma at $20 \mathrm{mTorr}$ with $750 \mathrm{~W}$ ICP power, $30^{\circ} \mathrm{C}$.

Fig. 4: Scanning electron micrographs of the etched emitters as a function of ICP power for; (a) $700 \mathrm{~W}$, (b) $800 \mathrm{~W}$, and (c) $900 \mathrm{~W}$. (RF $45 \mathrm{~W}, \mathrm{SF}_{6} 60 \mathrm{sccm}, 30^{\circ} \mathrm{C}, 30 \mathrm{mTorr}, 770 \mathrm{~s}$ ) (d) Variation in emitter aspect ratio and etch rate as a function of ICP power 
Fig. 5: (a) Typical I-V curves of sample 1(b) Corresponding FN plot. Process parameters: ICP $500 \mathrm{~W}, \mathrm{RF} 20 \mathrm{~W}, 30^{\circ} \mathrm{C}, \mathrm{SF}_{6} 30 \mathrm{sccm}, 20$ mTorr, $820 \mathrm{~s}$, circular mask $(2.5 \mu \mathrm{m})$ (c) I-V curves of second Mo-FEAs, (d) Corresponding FN plot. Process parameters: ICP 800 $\mathrm{W}, \mathrm{RF} 40 \mathrm{~W}, 40^{\circ} \mathrm{C}, \mathrm{SF}_{6} 40 \mathrm{sccm}, 10 \mathrm{mTorr}, 940 \mathrm{~s}$, circular mask $(2.0 \mu \mathrm{m})$ 


\section{References}

[1] E. Kirk, S. Tsujino, T. Vogel, K. Jefimovs, J. Gobrecht, A. Wrulich, Fabrication of all-metal field emitter arrays with controlled apex sizes by molding, Journal of Vacuum Science \& Technology B, 27 (2009) 1813-1820.

[2] M. Nakamoto, K. Fukuda, Highly integrated field emitter arrays fabricated by transfer mold technique, Japanese journal of applied physics, 42 (2003) 3611.

[3] M. Nakamoto, J. Moon, Stable, ruggedized, and nanometer-order size transfer mold field emitter array in harsh oxygen radical environment, Journal of Vacuum Science \& Technology B, 33 (2015) 03C107.

[4] C. Spindt, A thin-film field-emission cathode, Journal of Applied Physics, 39 (1968) 3504-3505.

[5] C. Spindt, I. Brodie, L. Humphrey, E. Westerberg, Physical properties of thin-film field emission cathodes with molybdenum cones, Journal of Applied Physics, 47 (1976) 5248-5263.

[6] M. Nagao, K. Utsumi, Y. Gotoh, H. Tsuji, J. Ishikawa, T. Nakatani, T. Sakashita, K. Betsui, Dependence of emission characteristics of Spindt-type field emitters on cathode material, Applied surface science, 146 (1999) 182-186.

[7] H. Kim, S.-W. Seo, J.-W. Lee, J.-W. Park, Y.-H. Lee, J. Jang, B.-K. Ju, Enhancement of emission characteristics for field-emitter arrays by optimizing the etched feature of the gate electrode, Journal of Vacuum Science \& Technology B, 21 (2003) 186-192.

[8] H. Kim, S.-W. Seo, J.-W. Park, Y.-H. Lee, J. Jang, B.-K. Ju, Development of a coldcathode electron gun for cathode-ray tube using a Mo-tip field-emitter array, Journal of Vacuum Science \& Technology B, 21 (2003) 43-47.

[9] J. Choi, H. Jeong, D. Pflug, A. Akinwande, H. Smith, Fabrication of $0.1 \mu \mathrm{m}$ gate aperture Mo-tip field-emitter arrays using interferometric lithography, Applied physics letters, 74 (1999) 3050-3052.

[10] N. Zhu, K. Xu, L. Song, X. Chen, J. Chen, Fabrication and characterization of bulk molybdenum field emission arrays, Solid-State Sensors, Actuators and Microsystems (TRANSDUCERS), 2015 Transducers-2015 18th International Conference on, IEEE, 2015, pp. 1168-1171.

[11] K.X. Ningli Zhu, Yusheng Zhai, Zhi Tao, Yunsong Di, Zhipeng Zhang, Jun Chen, Matthew T. Cole, William I. Milne, \& Jing Chen, Bulk Molybdenum Spindt Field Emission Arrays (Rapid Communication), Functional Nanostructures, 2016, pp. 4. [12] A.A. Fomani, S.A. Guerrera, L.F. Velasquez-Garcia, A.I.T. Akinwande, Toward amp-level field emission with large-area arrays of Pt-coated self-aligned gated nanoscale tips, Electron Devices, IEEE Transactions on, 61 (2014) 2538-2546.

[13] S. Huq, L. Chen, P. Prewett, Sub10nm silicon field emitters produced by electron beam lithography and isotropic plasma etching, Microelectronic engineering, 27 (1995) 95-98.

[14] M. Rakhshandehroo, S. Pang, Fabrication of Si field emitters by dry etching and mask erosion, Journal of Vacuum Science \& Technology B, 14 (1996) 612-616.

[15] M. Rakhshandehroo, F. Sukardi, S. Pang, Simulation and dry etching of field emitter tips in Si, Journal of Vacuum Science \& Technology A, 14 (1996) 1832-1838.

[16] T. Asano, D. Sasaguri, E. Shibata, K. Higa, Ion beam modification of a photoresist and its application to field emitters, Japanese journal of applied physics, 36 (1997) 7749. 
[17] A. Baba, M. Hizukuri, M. Iwamoto, T. Asano, Stamp technology for fabrication of field emitter from organic material, Journal of Vacuum Science \& Technology B, 18 (2000) 877-879.

[18] F. Ducroquet, P. Kropfeld, O. Yaradou, A. Vanoverschelde, Fabrication and emission characteristics of GaAs tip and wedge-shaped field emitter arrays by wet etching, Journal of Vacuum Science \& Technology B, 16 (1998) 787-789.

[19] C.-C. Wang, T.-K. Ku, I.-J. Hsieh, H.-C. Cheng, Fabrication and characterization of the Pd-silicided emitters for field-emission devices, JAPANESE JOURNAL OF APPLIED PHYSICS PART 1-REGULAR PAPERS SHORT NOTES \& REVIEW PAPERS, 35 (1996) 3681-3685.

[20] W. Choi, J.J. Cuomo, V. Zhirnov, A. Myers, J. Hren, Field emission from silicon and molybdenum tips coated with diamond powder by dielectrophoresis, Applied physics letters, 68 (1996) 720-722.

[21] Y. Kurogi, K. Kamimura, Molybdenum Etching Using CCl4/O2 Mixture Gas, Japanese Journal of Applied Physics, 21 (1982) 168.

[22] R. Saia, B. Gorowitz, The reactive ion etching of molybdenum and bilayer metallization systems containing molybdenum, Journal of the Electrochemical Society, 135 (1988) 2795-2802.

[23] J. Sharma, S. Fernando, W. Deng, N. Singh, W. Tan, Molybdenum etching using an $\mathrm{SF} 6, \mathrm{BCl} 3$ and Ar based recipe for high aspect ratio MEMS device fabrication, Journal of Micromechanics and Microengineering, 23 (2013) 075025.

[24] J. Hu, Y. Zhang, S. Chen, S. He, N. Li, J. Chen, Inductively coupled plasma etching of bulk molybdenum, Micro Electro Mechanical Systems (MEMS), 2012 IEEE 25th International Conference on, IEEE, 2012, pp. 267-270.

[25] K.R. Williams, K. Gupta, M. Wasilik, Etch rates for micromachining processingPart II, Microelectromechanical Systems, Journal of, 12 (2003) 761-778.

[26] R. Shul, G. McClellan, R. Briggs, D. Rieger, S. Pearton, C. Abernathy, J. Lee, C. Constantine, C. Barratt, High-density plasma etching of compound semiconductors, Journal of Vacuum Science \& Technology A, 15 (1997) 633-637.

[27] A.A. Talin, K.A. Dean, J.E. Jaskie, Field emission displays: a critical review, Solid State Electronics, 45 (2001) 963-976.

[28] C.A. Spindt, C.E. Holland, A. Rosengreen, I. Brodie, Field-emitter-array development for high-frequency operation, Journal of Vacuum Science \& Technology B, 11 (1993) 468-473. 

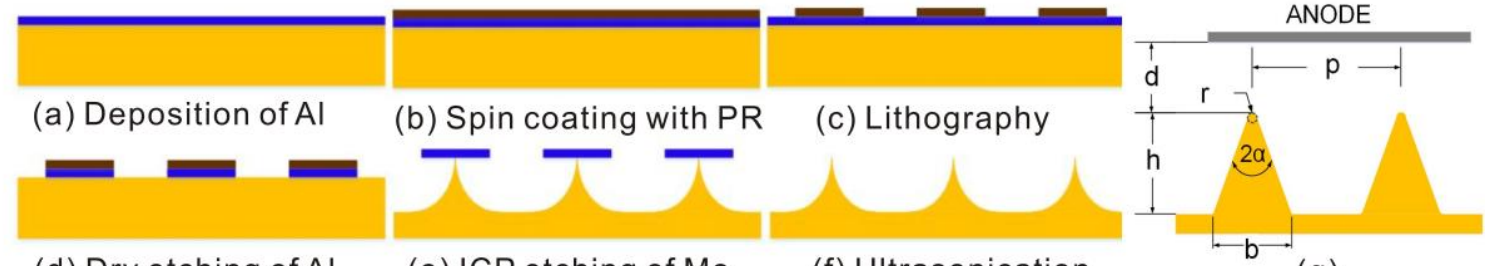

(d) Dry etching of $\mathrm{Al}$

(b) Spin coating with PR

(c) Lithography
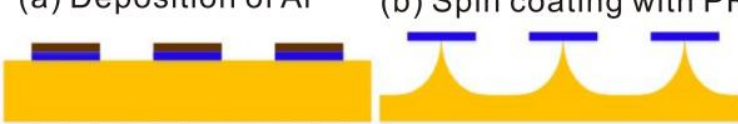

(e) ICP etching of Mo

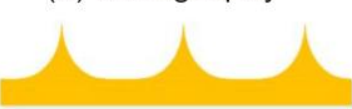

(f) Ultrasonication

(g)

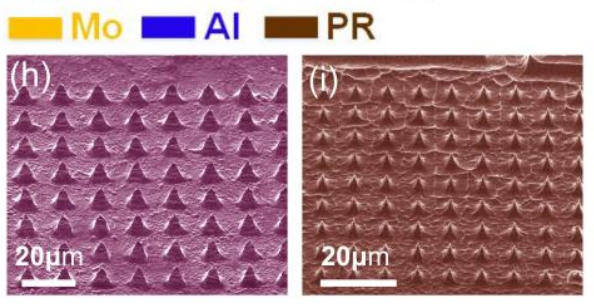

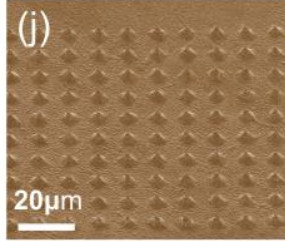

Fig. 1
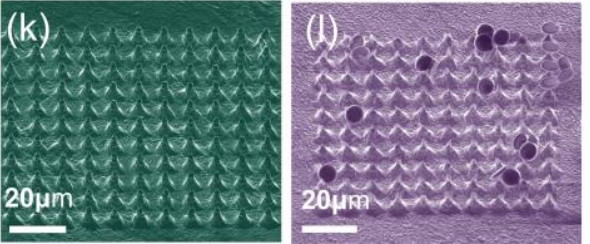
(a)

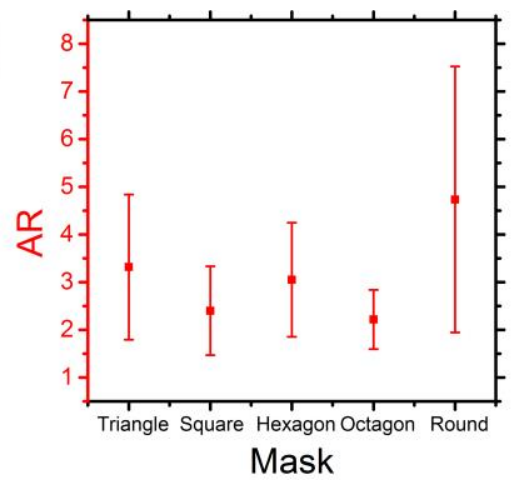

(b)

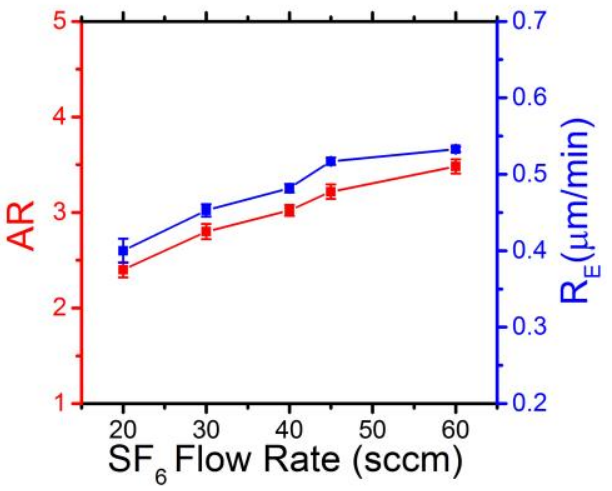

(c)

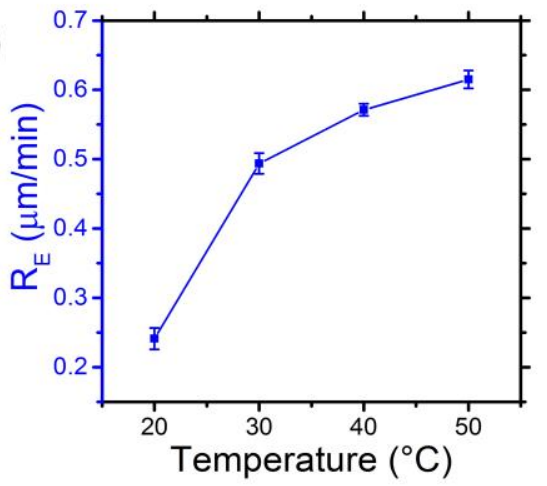

(d)

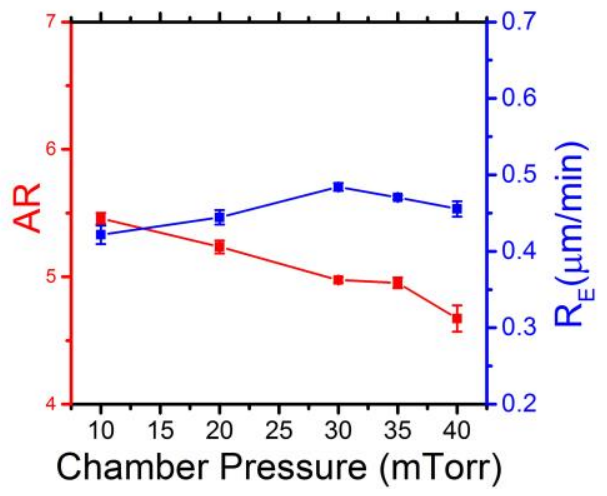

Fig. 2 

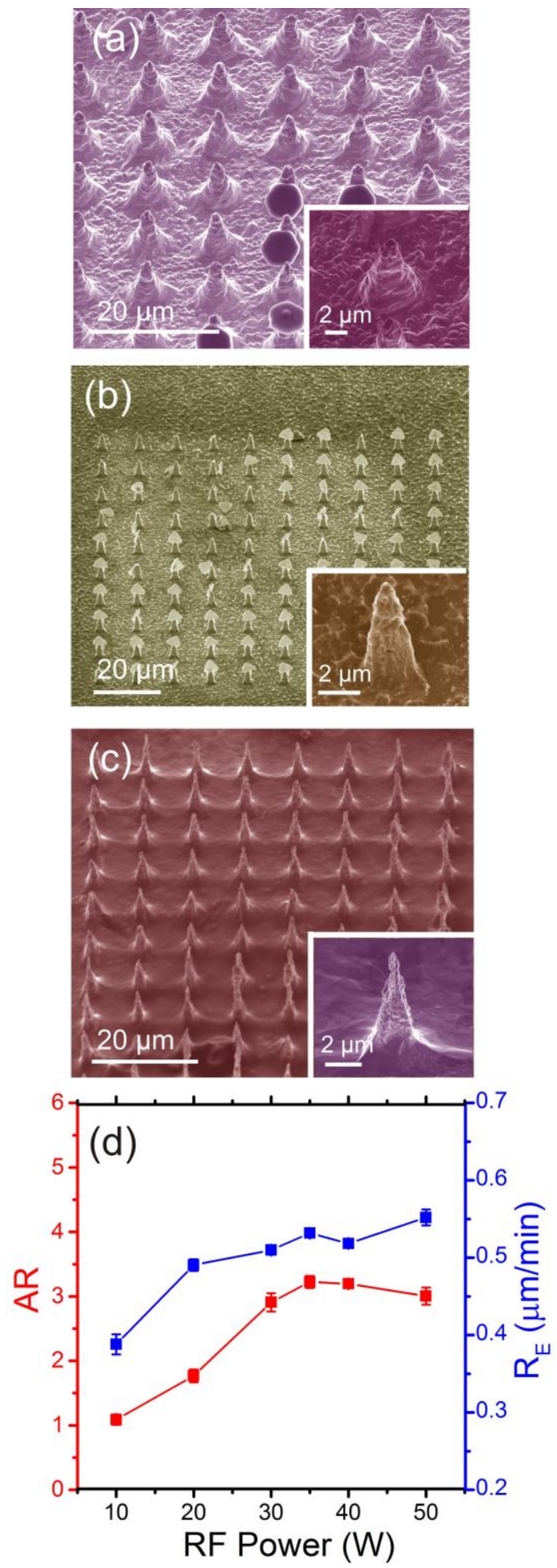

Fig.3 

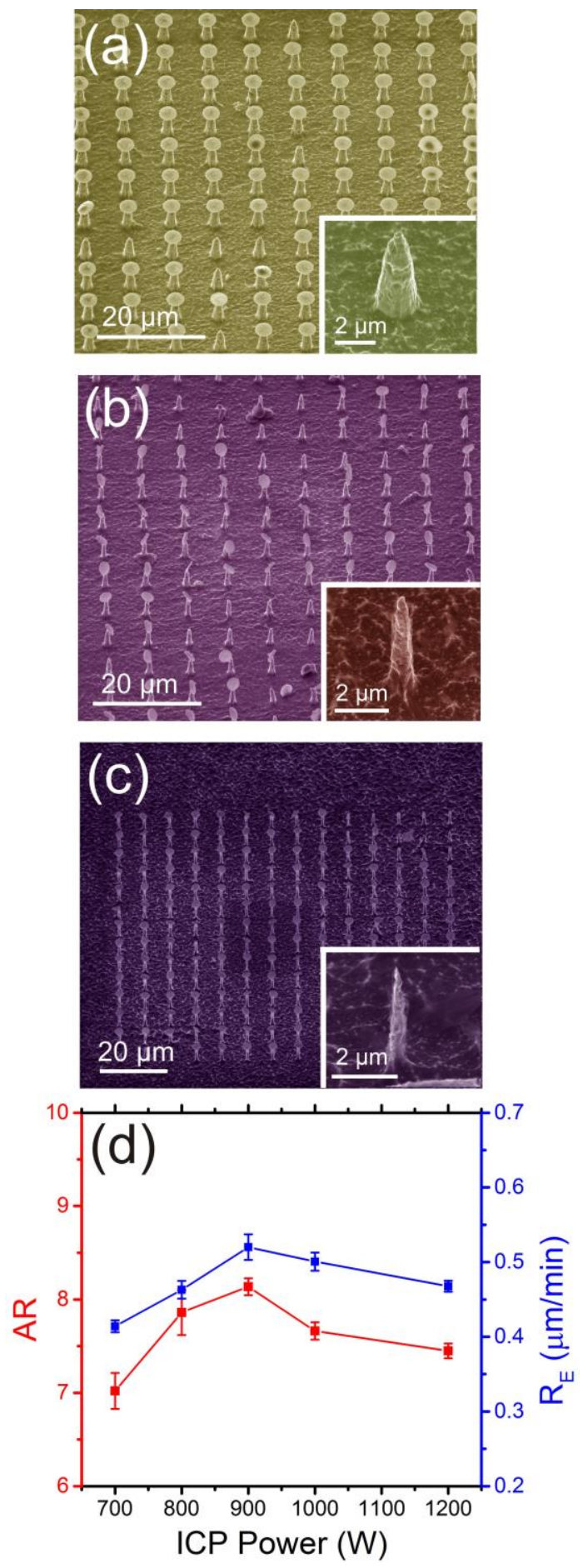

Fig.4 
(a)

a)

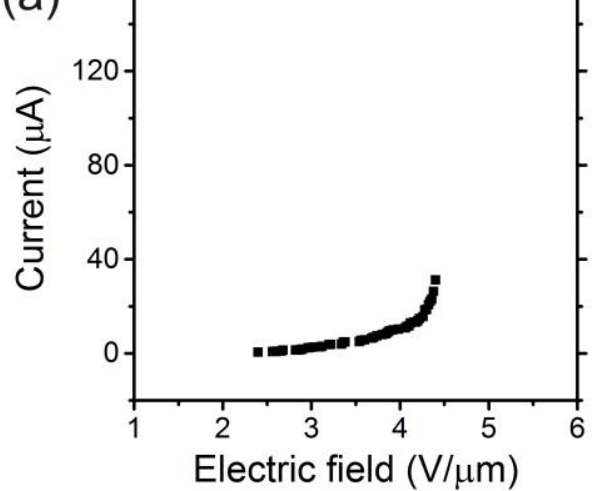

(c)

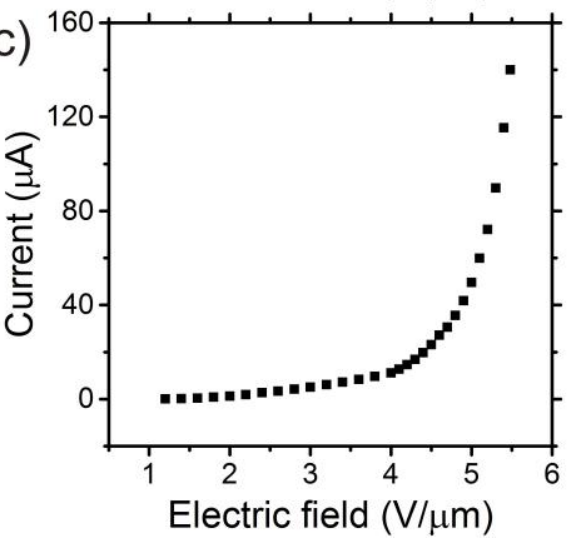

(b)

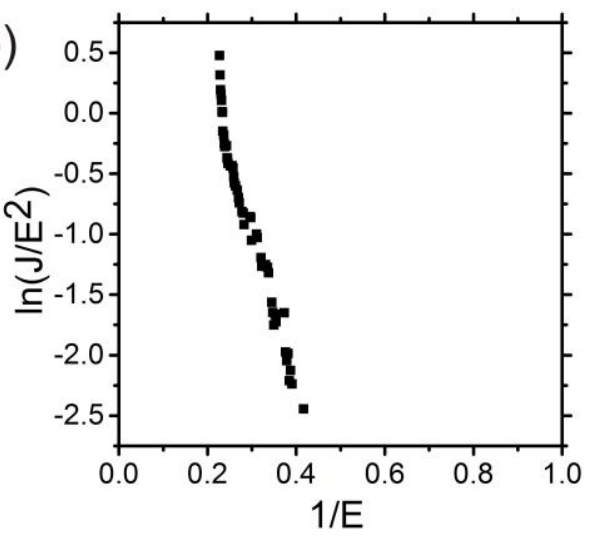

(d)

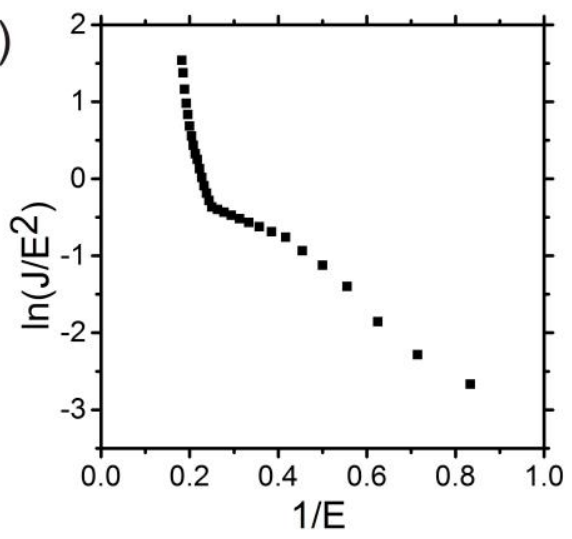

Fig. 5 